\title{
Proceso de edición de un manuscrito de Ramón Menéndez Pidal: Etapas en la vida y obra de Menéndez Pelayo
}

\author{
Sara SÁNCHEZ BELLIDO \\ Fundación Ramón Menéndez Pidal \\ Instituto Universitario Menéndez Pidal \\ ssbellido@pdi.ucm.es
}

\section{RESUMEN}

En 1914, Ramón Menéndez Pidal fue invitado por la Institución Cultural Española de Buenos Aires para dar una serie de conferencias en homenaje a Marcelino Menéndez Pelayo. El texto de estas conferencias, en su mayor parte inédito, fue reelaborado por el autor en años posteriores con intención de publicarlo en forma de libro. Dicho proyecto quedó abortado y solo ahora ha sido recuperado en la Fundación Ramón Menéndez Pidal con el objeto de realizar una edición crítica del mismo.

Este artículo tiene como objetivo precisamente dar a conocer el estado del manuscrito, así como esbozar su contenido, los problemas de edición que presenta y las posibles soluciones que se han planteado. Se trata de un anuncio de lo que podrá encontrarse más adelante, cuando la edición esté concluida.

Palabras clave: Edición, Menéndez Pidal, Menéndez Pelayo, Manuscrito.

\begin{abstract}
In 1914, Ramón Menéndez Pidal was invited to give a series of lectures in honor of Marcelino Menéndez Pelayo by the Spanish Cultural Institution of Buenos Aires. The text of these lectures, was rewrited by the author later with the intention of publishing it like a book. The project was aborted and only now it has been resumed in the Fundación Ramón Menéndez Pidal in order to make a critical edition.

This article wants to explain the state of the manuscript as well as summarize its content, its editing problems and the possible solutions that have been raised. This is an announcement of what will be found later when editing is completed.
\end{abstract}

Keywords: Edition, Menéndez Pidal, Menéndez Pelayo, Manuscript. 
En el último número del Boletín de la Biblioteca de Menéndez Pelayo, correspondiente al año 2012, Antonio Cid daba a conocer el hallazgo, entre los documentos conservados en la Fundación Ramón Menéndez Pidal, de un manuscrito de este autor cuyo contenido se consideró mayoritariamente inédito. Se trata de un trabajo sobre la figura de Marcelino Menéndez Pelayo.

Sobradamente conocida es la admiración que profesaba Pidal hacia su maestro y, por ello, en esa misma publicación señalaba el profesor Cid la rareza de los pocos escritos a él dedicados de los que se tenía noticia:

Si se examina la bibliografía más completa de Menéndez Pidal, la publicada por María Luisa Vázquez de Parga en 1966, puede sorprendernos el que, a juzgar por ella, con excepción de la reseña que acabamos de mencionar y un breve artículo de enciclopedia, Menéndez Pidal no publicara nada en su larga vida sobre el estudioso de quien se reconoció discípulo devoto (...). Es cierto que en la bibliografía de 1966 es incompleta y que, en lo que ahora nos interesa, deben subsanarse al menos dos omisiones. La primera es un artículo necrológico (...). La otra es una conferencia pronunciada y publicada en 1956 (...). Pero aún con estas salvedades seguiría pareciendo escasa la contribución de Menéndez Pidal a la glosa de un maestro de quien se consideraba heredero $(. . .)^{1}$.

La razón para este vacío sería, también según el profesor Cid, "que había decidido dedicar un libro completo al estudio de toda la obra de Menéndez Pelayo" ${ }^{2}$. Ese libro es precisamente el objeto de este trabajo con el que se pretende describir el ejemplar y su estado de conservación, concretar un poco más la visión que Menéndez Pidal tenía de la obra y su maestro, y establecer el punto de partida de un proyecto de edición de la misma.

El manuscrito en cuestión puede considerarse como un borrador autógrafo compuesto, ya que no todos los materiales pertenecen al mismo trabajo (aunque sí parece que se utilizarían todos para dar forma a lo que iba a ser el texto definitivo), presenta numerosas correcciones y no está encuadernado ${ }^{3}$. Se compone en su mayor parte de 309 cuartillas de papel lineado de 170 x $250 \mathrm{~mm}$, además de otras de 198 x $239 \mathrm{~mm}$, cuya datación parece más antigua que las del resto. Entre todas ellas se intercalan otras 250 hojas, generalmente de menor tamaño, con materiales complementarios y unas cuartillas de color marrón que funcionan a modo de separador entre algunas partes. Todas ellas contienen anotaciones.

\footnotetext{
${ }^{1}$ A. Cid Martínez (2012), pp. 40-41.

${ }^{2}$ A. Cid Martínez (2012), p. 41.

${ }^{3}$ Para la elaboración de esta descripción general del manuscrito se han tenido en cuenta las pautas dadas por Elisa Ruiz en su Manual de Codicología y por Alberto Blecua en su Manual de Crítica textual, aunque adaptadas al caso concreto de este testimonio (véanse E. Ruiz (1988) y A. Blecua (1983)).
} 
La escritura se limita principalmente al recto de las cuartillas, respetando el margen dado por la página, aunque en algunas ocasiones se recurre a este o al verso para introducir añadidos o notas. La letra es mayoritariamente autógrafa de Menéndez Pidal, pero también hay muestras de escritura de María Goyri, de José Ramón Lomba y Pedraja y de Américo Castro. El cuerpo principal del texto debió de redactarse en torno a 1914, aunque se conservan fragmentos de una fecha anterior (seguramente 1912) y posterior (1956), tal y como se explicará a continuación.

Cada una de las cuartillas presenta además una numeración en la esquina superior izquierda que varía de unos bloques a otros (es solo parcialmente consecutiva) $\mathrm{y}$ en muchas ocasiones aparece corregida, lo que supone una de las muestras de los numerosos cambios y revisiones realizados por el autor. Aún así, el uso de un determinado sistema de colores ha permitido establecer un aparente orden y distinguir una posible estructura dentro de la obra.

Se han distinguido ocho grandes bloques a partir de la separación que presenta de acuerdo con las cuartillas marrones y la numeración. Esto no significa que se trate de una organización plenamente válida, sino solo un mecanismo para facilitar el estudio y seguimiento de los materiales a partir de una digitalización realizada con anterioridad a la transcripción y que refleja el estado en que se conservaba el manuscrito. En realidad, se observa cierto desorden entre las partes, que se resolverá en la edición, pero se ha creído oportuno respetar por el momento.

\begin{tabular}{|c|c|}
\hline 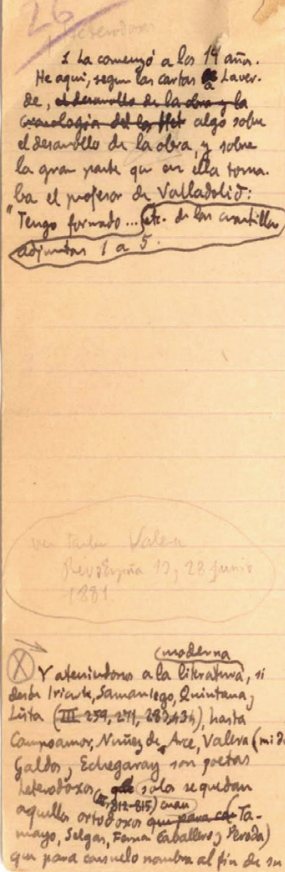 & 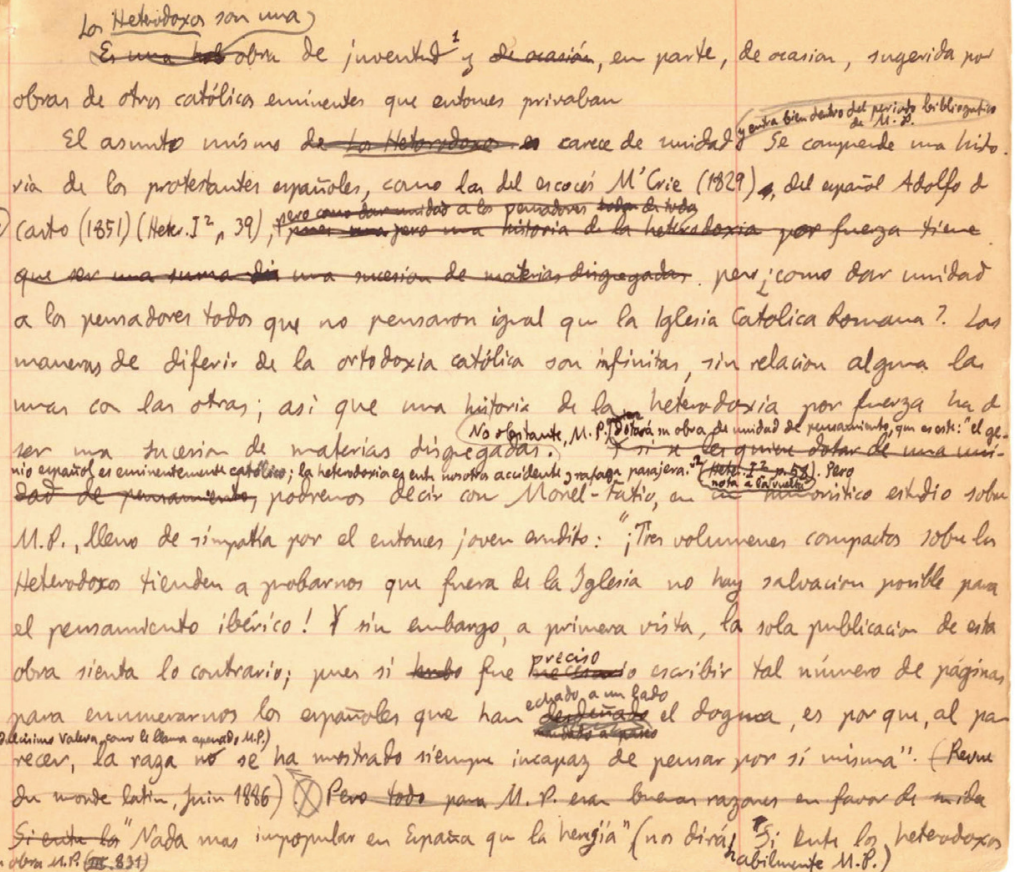 \\
\hline
\end{tabular}


La mayoría del texto recoge, como ya señaló Antonio Cid, el contenido de una serie de catorce conferencias que Ramón Menéndez Pidal dio en la Institución Cultural Española de Buenos Aires en 1914 . En ellas se revisa la idea comúnmente asentada de que Menéndez Pelayo tuvo un pensamiento monolítico a lo largo de su vida. La tesis de Pidal es que, muy al contrario, don Marcelino cambió notablemente sus gustos y pareceres a medida que sus estudios avanzaban, de lo cual dejó buena muestra en sus obras. Para demostrarlo, realizó una revisión de sus trabajos, distinguiendo cuatro etapas: una de formación y espíritu polémico, en la que se incluirían la Historia de los Heterodoxos, la Ciencia española, el Horacio en España, las conferencias sobre Calderón y sus creaciones poéticas; una segunda de evolución o transición, en la que escribiría la Historia de las Ideas Estéticas; la tercera, de rectificación y plenitud, donde comienza la publicación de la Antología de Liricos y las Obras de Lope, y la última de decaimiento, en la que compone los Orígenes de la novela. También se incluye, a modo de final, una semblanza bastante emotiva de la figura del maestro y una reflexión sobre la importancia de su trabajo en relación con sus predecesores.

Aparte de esto, los bloques tercero y cuarto de la digitalización incluyen versiones más breves de la misma idea, que parece recurrente a lo largo de la trayectoria de Pidal. En el primer caso, se trata de una primera redacción del discurso de don Ramón en el Instituto de España en $1956^{5}$, y en el segundo, de un texto anterior que corresponde a otra intervención de este en el Ateneo de Madrid en 1912, en un acto de homenaje tras el fallecimiento de Menéndez Pelayo. Igualmente se conservan en el mismo manuscrito un autógrafo de José Ramón de Luanco sobre la vida de Me-

${ }^{4}$ El texto de estas conferencias ha permanecido inédito hasta el momento. Solo se publicó un resumen cuyo borrador también se conserva entre los materiales manejados (véase Anales de la Institución Cultural Española (1947)).

${ }^{5}$ Antonio Cid señala también que precisamente esta conferencia pudo marcar el último intento de Menéndez Pidal por retomar el libro y que, quizás al conocer el trabajo de Dámaso sobre el asunto y descubrir con desaliento la imagen que del maestro daba la prensa española en el centenario de su muerte, decidió abandonar definitivamente el proyecto: "no hay duda de que le desagradó la instrumentalización sectaria que se hizo de la figura de Menéndez Pelayo (...). En consecuencia, Menéndez Pidal, (sic) se limitó a publicar las breves páginas de su conferencia en el Instituto de España, pronunciada en calidad de Director de la Real Academia, y aun así confiesa que pensó modificar a última hora las cuartillas que tenía previsto leer. La razón es que unos días antes su antiguo discípulo Dámaso Alonso había anticipado en una conferencia universitaria lo que sería su breve y célebre libro Menéndez Pelayo, crítico literario (Las palinodias de don Marcelino), aparecido en el mismo año 1956. Las palinodias o "rectificaciones" de Menéndez Pelayo eran, precisamente, una de las idea-fuerza que servían de hilo conductor al libro que Pidal tenía en el taller hacía tantos años. (...) es muy verosímil que Menéndez Pidal considerase que su libro había perdido parte esencial de su novedad, y renunciara definitivamente a terminarlo y publicarlo" (A. Cid Martínez (2012), pp. 46-47). 
néndez Pelayo y varios recortes de prensa, en su mayoría del año 1956, en que se celebró el aniversario del nacimiento del autor.

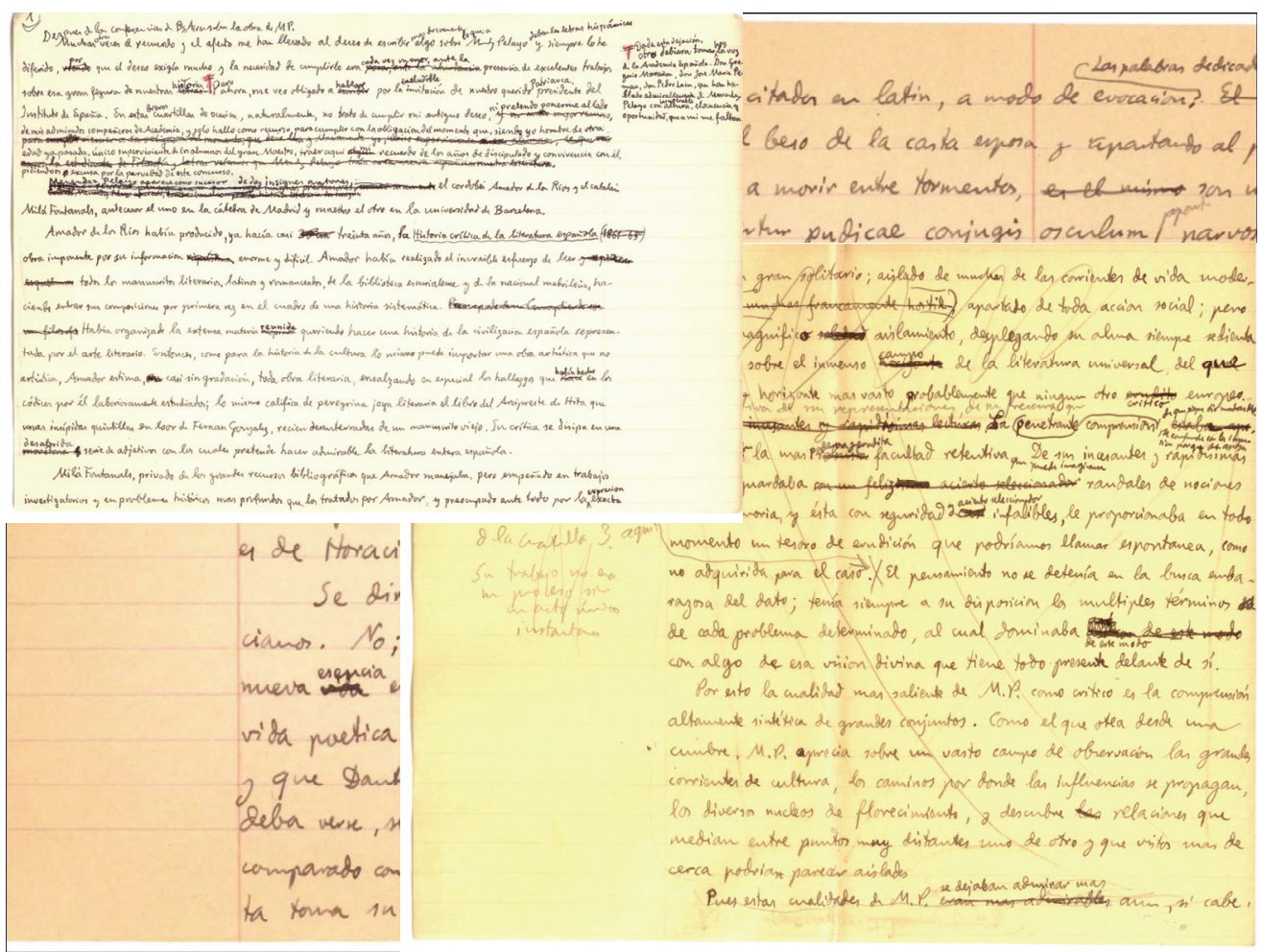

Por último, cabe destacar que en la actualidad el original está incompleto, ya que se observa la falta de algunas cuartillas del bloque correspondiente a la visión de Lope de Vega, que sabemos sí debió formar parte del original en su primera redacción por la correlación de la numeración. No se descarta, no obstante, que en un futuro pueda subsanarse esta falta, ya que aún no se han podido catalogar e inventariar totalmente los fondos de la FRMP y es posible que tales cuartillas se incorporaran con posterioridad a otros materiales de trabajo de Pidal.

Así pues, como puede verse, el material con que se cuenta para la edición es heterogéneo y presenta notables problemas. El primero de ellos y fundamental es el de que el manuscrito no constituya una obra acabada, sino en proceso de redacción definitiva. Lo que conservamos son tres versiones de una misma idea de las que debía resultar un texto único. Además, casi la totalidad de estas páginas contienen a su vez enmiendas y tachaduras de carácter diverso e introducidas en diferentes momentos. Se aprecia con claridad que hay cuartillas rescritas total o parcialmente, que 
repiten con modificaciones párrafos anteriores o posteriores. En algunos casos incluso se aprecia la pérdida de algunas de las que sirvieron de base para la redacción actual, ya que no se conserva el inicio o el final de algunas frases. En otras ocasiones, las tachaduras se extienden por toda la página, pero se observa claramente que parte del texto no puede eliminarse puesto que se pierde el sentido del discurso.

Por otro lado, no hay seguridad tampoco de cuáles de esas cuartillas habían sido revisadas más o menos definitivamente y cuáles no. Varios de los bloques presentan cuantiosas modificaciones, algunas de época claramente tardía, mientras que otros solo incluyen mínimos cambios que pueden datar de la primera redacción del texto. El sentido permite apreciar que ciertas pequeñas modificaciones (cambios de orden de palabras, uso de sinónimo) se produjeron en el momento mismo de la escritura, ya que no se disturba la línea, pero no siempre puede asegurarse que esa cuartilla refleje la redacción original. Igualmente, solo en ocasiones parece distinguirse un cambio en la tinta o en la letra que puede denotar una revisión a partir de una relectura posterior. Ni siquiera el uso ocasional del lápiz es completamente fiable, pues también parece ubicarse en momentos diversos.

A todo ello debe añadirse también la incógnita de los materiales adicionales, numerosas notas y recortes de periódico que Pidal recopiló e intercaló en el texto principal sin indicación, en la mayoría de los casos, de cuál sería su lugar definitivo. Aún no ha sido posible examinarlos todos, es cierto, pero una primera aproximación revela que servían de materiales preparatorios. En ellos, cuya procedencia material es diversa, don Ramón recogía breves citas o ideas a partir de las cuales desarrollaba posteriormente el discurso. En ocasiones, esas citas se añadían al texto (mediante indicación de incluir determinada nota o copiándolas), pero en otras no hay señal explícita de su uso. Algunos de ellos, además, presentan citas extensas y resúmenes de otras obras encargados, al parecer, a su esposa María Goyri o algún amigo, como Américo Castro. 


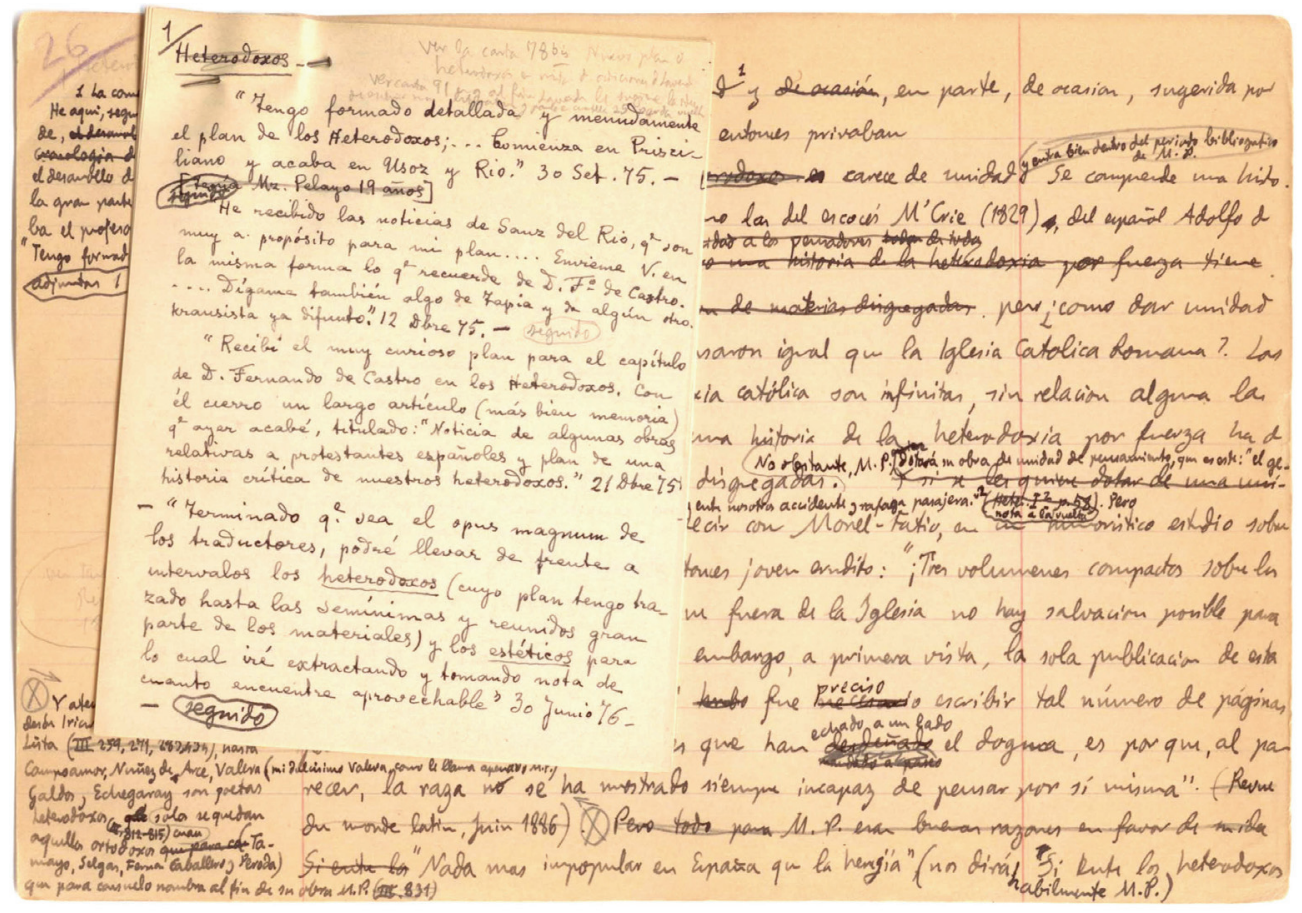

Todo esto pone de manifiesto los problemas que supone enfrentarse a la edición de una obra de tales características. Por ello, la primera cuestión que debe plantearse el editor es el tipo de edición que resulta más adecuada, ya que esta decisión condicionará la metodología de trabajo.

Dado que se trata de una obra del siglo XX, puede parecer en un primer momento que la labor de edición presenta menos complicaciones que la de un texto clásico, pero acabamos de ver que en este caso no es así. El hecho de que no se conserve una versión definitiva y acabada supone que deben tomarse numerosas precauciones al respecto y plantearse ciertas cuestiones: ¿qué texto se edita? ¿Qué variantes deben tenerse en cuenta y cómo deben consignarse en el correspondiente aparato? ¿Cómo distinguir las notas que el propio autor introduce de las posteriores del Editexte caso concreto, y dada la cantidad de información existente sobre el proceso de escritura, se planteó la posibilidad de realizar una edición de tipo geneticista. Los presupuestos de la crítica genética establecen que el manuscrito moderno debe ser objeto de una edición y estudio que ponga de relieve su importancia dentro del mecanismo de escritura, es decir, que sirva para mostrar el proceso de creación del autor. Parte esta escuela de la idea de que, en su mayoría, los textos contemporáneos presentan una versión impresa que ofrece el texto en su versión definitiva, 
por lo que el manuscrito "queda circunscripto al ámbito privado del escritor" . Así, la publicación del manuscrito o manuscritos originales presenta la ventaja de ofrecer al lector y al estudioso una historia, por así decirlo, de la propia visión que el autor tiene de su obra a partir de los cambios que él mismo establece o incluso los comentarios o glosas marginales de que se pudo servir en el proceso. Para lograrlo, el crítico geneticista realiza una labor no solo de trascripción de cada una de las variantes, sino también de análisis e interpretación del momento y la motivación de los cambios. $\mathrm{Y}$ es que estas revisiones pueden denotar tanto preferencias estéticas como, en algunos casos, condicionamientos socio-culturales: "La textualización no surge ex nihilo: en todo proceso de escritura se reproducen discursos sociales o se los transforma"7.

El problema se presenta cuando, como ocurre en este caso, no se conserva una versión definitiva, ya que se trata de un proyecto abortado, y el dossier (sirviéndonos de la terminología habitual en la crítica genética) muestra tales complicaciones como las ya señaladas. Si lográramos descifrar el aparente caos de correcciones y adiciones y organizarlas cronológicamente, como establece la metodología genética, y quisiéramos incorporar mediante la presentación gráfica habitual todas las variantes que presenta el texto, el resultado sería prácticamente ilegfilsleierto que resulta enormemente interesante comprobar el modo de trabajo del autor y el proceso de redacción empleado, pero conviene preguntarse si en este caso representa una verdadera ventaja para el lector. No en vano, cualquier edición se realiza con el fin de que aporte algo a quien la lea. Cuando el público tiene a su disposición un texto previo acabado y limpio no existe este inconveniente, pero cuando, como aquí ocurre, se trata de un inédito de enorme interés por su contenido y de gran extensión quizás conviene dar prioridad al sentido, dejar que el lector conozca la obra antes de abrumarlo con todas las posibilidades barajadas por el autor. No en vano, la propia Élida Lois reconoce que "La lectura de estas ediciones es sumamente dificultosa. Se trata de repertorios instrumentales destinados, fundamentalmente, a otros geneticistas o a los estudiosos interesados por ahondar en un pasaje o en un capítulo de una obra"8.

Así pues, se decidió que lo más idóneo para esta obra sería realizar una edición de tipo filológico tradicional, lo cual no quiere decir que de este modo se resuelvan todos los problemas que plantea el texto.

De acuerdo con la terminología de Blecua, el ejemplar de que disponemos es un borrador, es decir, que "presenta siempre correcciones abundantes por lo general; o lo que es lo mismo, da un texto en las distintas etapas de creación"9. Aunque debe

\footnotetext{
${ }^{6}$ E. Lois (2012), p. 47.

${ }^{7}$ E. Lois (2001), p. 35.

${ }^{8}$ E. Lois (2001), p. 11.

${ }^{9}$ A. Blecua (1983), p. 39.
} 
tenerse en cuenta que incluye tres versiones más o menos autónomas que, como se ha señalado, se corresponden con tres redacciones sucesivas (1912, 1914 y 1956), pero que, a su vez, constituyen los materiales de dicho borrador.

¿Qué debe editarse, pues? ¿La última versión de 1956, la primera de 1912 o todo el texto? En realidad, parece que la intención de Menéndez Pidal era la de convertir las catorce conferencias en una obra unitaria para la que se apoyaría en esa otra versión previa y en todas las notas y recortes que acompañan al texto, mientras que la versión de 1956 se justifica por la necesidad de pronunciar unas palabras en el homenaje y no recogen más que un resumen de las ideas principales del conjunto. De este modo, parece lo más conveniente realizar la edición tomando como base las cuartillas correspondientes a las conferencias y considerar el resto de materiales como documentos de apoyo.

Ahora bien, ¿debe ofrecerse un texto único o conviene registrar todas esas variantes de las que ya se ha hablado? A priori, la respuesta de un filólogo sería la de consignar en un aparato crítico todas las versiones y los cambios de redacción. Algo en lo que también estaría de acuerdo un geneticista, ya que, como señala Javier Lluchs-Prats, "siempre que haya materiales genéticos a disposición del filólogo, la edición crítica, como en esencia se define (aquella establecida sobre la base documentada de todos los testimonios e indicios accesibles de un texto), ha de explorar y utilizar el dossier" ${ }^{10}$. Sin embargo, el problema sería semejante al que se señalaba más arriba: la cantidad de notas necesarias para recoger todos los cambios dificultaría la lectura y convertiría el aparato crítico en un monstruo difícil de consultar.

Por todas estas razones, para la edición de este manuscrito, cuyo título se ha elegido a partir de una de las anotaciones del propio autor, se ha optado por una decisión seguramente discutible: se editará el texto corregido de las conferencias (teniendo en cuenta que la revisión del autor no parece que estuviera acabada), intentando mantener la división en capítulos que se desprende del sistema de colores de la numeración, y se seleccionarán para la elaboración del aparato crítico aquellas variantes que se consideren más significativas. Se ha decidido igualmente, para no multiplicar las llamadas de atención, mantener un solo aparato de notas al pie en el que se distinguirán mediante las siglas $N$. del $A$. o $N$. del E. las notas del autor y las del editor respectivamente. Por último, se incluirán a modo de anexos los materiales complementarios, entre los que se cuentan las otras dos versiones de 1912 y 1956. Se trataría, por tanto, de un volumen considerable, cuyo cuerpo central constaría, en principio, de cinco grandes capítulos, complementado con un aparato de notas y al que se añadiría un estudio preliminar en el que no solo se analizará el contenido, sino que se intentará dar cuenta de los cambios más importantes realizados por el autor y la motivación de los mismos cuando pueda establecerse. No debe olvidarse que las circunstancias históricas cambian sustancialmente entre las primeras redacciones y el

${ }^{10}$ J. Lluch-Prats (2012), p. 100. 
momento de las últimas revisiones, por lo que algunos de los cambios pueden ser resultado de la necesidad de atenuar ciertos comentarios ${ }^{11}$.

En definitiva, de este modo, puede ofrecerse al lector un texto fundamentalmente limpio y coherente, que le permita conocer el contenido de la obra, pero también hacerse una idea del proceso de creación seguido por el autor. No se descarta en un futuro realizar el estudio geneticista ya señalado, o incluso una edición multimedia que pueda incorporar las variantes en su lugar correspondiente, ya que esto podría suponer una valiosa herramienta para todo aquel que quiera comprender el modo de trabajo de Ramón Menéndez Pidal, pero por el momento, se ha optado por dar prioridad a la obra.

Aún así, en el proceso de primera transcripción del ejemplar se ha optado por recoger todas las variantes que presenta el original para asegurar que no se pierde información de posible relevancia. Por ello, se ha establecido un sistema de marcas y notas al final de cada capítulo que muestran las diferentes versiones e incluyen apreciaciones del editor sobre las posibles implicaciones de la letra, etc. También se marca entre corchetes el inicio de cada nueva cuartilla, a la que se da una numeración según el bloque de la digitalización en que se incluye y la posición dentro de ese bloque. Además, se incluye entre paréntesis la numeración original, lo que permite identificar las cuartillas más rápidamente y puede servir para el futuro análisis cronológico de las correcciones. Por ejemplo: la cuartilla quince del bloque 1 , que es una de las que ha sufrido un proceso de rescritura, se señala como [1.15 (14/1 bis/2 y 3)]. Igualmente, se marcan las hojas de notas que aparecen intercaladas en su lugar correspondiente, mediante un sistema similar de corchetes, pero usando esta vez letras en lugar de número, por ejemplo, [1.c]. Por último, se indican mediante comentarios los cambios de letra (generalmente de Menéndez Pidal a María Goyri y viceversa), y las anotaciones al margen de Pidal indicando suprimir un pasaje o restituirlo.

Así pues, cuando este proceso esté concluido, se procederá a determinar el lugar correspondiente de los materiales que aún no han podido ser ordenados y se determinará qué tipo de correcciones conviene consignar definitivamente en el aparato de variantes. De este modo, si más adelante se considera necesario retomar la idea de la edición genética, nos habremos asegurado de que el trabajo realizado no haya sido en vano y que no sea necesario comenzar de nuevo. Del mismo modo, los materiales estarán disponibles para quien se considere capacitado de emprender tal empresa. Pero por el momento, lo único que puede asegurarse es que una edición filológica verá la luz posiblemente el año próximo.

\footnotetext{
${ }^{11}$ Puede ser precisamente esta la razón por la que se tacha, por ejemplo, un amplio pasaje de alabanza a Giner de los Ríos.
} 


\section{Obras citadas}

Anales de la Institución Cultural Española, tomo I, Buenos Aires, Institución Cultural Española, 1947, pp. 50-71.

BleCUA, Alberto: Manual de crítica textual, Madrid, Castalia, 1983.

CID MARTíneZ, Jesús Antonio: "Menéndez Pelayo ante el Romancero (Introducción a unas páginas inéditas de Ramón Menéndez Pidal sobre la Antología de Poetas Líricos)", Boletín de la Biblioteca de Menéndez Pelayo, LXXXVIII, $\mathrm{n}^{\circ} 1$ (enero-junio 2012), pp. 35-48.

LLUCH-PRATS, Javier: "El obrador del escritor y la edición filológica del texto literario contemporáneo", en Bénédicte Vauthier y Jimena Gamba Corradine (eds.), Crítica genética y edición de manuscritos hispánicos contemporáneos, Salamanca, Ediciones Universidad de Salamanca, 2012, pp. 97-112.

LoIS, Élida: Génesis de escritura y estudios culturales. Introducción a la crítica genética, Buenos Aires, Edicial, 2001.

---, "Los estudios de crítica genética en el campo de la literatura hispanoamericana", en Bénédicte Vauthier y Jimena Gamba Corradine (eds.), Crítica genética y edición de manuscritos hispánicos contemporáneos, Salamanca, Ediciones Universidad de Salamanca, 2012, pp. 45-63.

RUIZ, Elisa: Manual de codicología, Salamanca-Madrid, Fundación Germán Sánchez Ruipérez-Pirámide, 1988. 